Mechanisms of Syntactic Change 
THIS PAGE INTENTIONALLY LEFT BLANK 


\section{Mechanisms of Syntactic Change}

Edited by Charles N. Li 
For reasons of economy and speed this volume has been printed from camera-ready copy furnished by the editor, who assumes full responsibility for its contents.

International Standard Book Number 0-292-75035-8

Library of Congress Catalog Card Number 77-82263 Copyright (C) 1977 by the University of Texas Press All rights reserved Printed in the United States of America 